\title{
Increasing the Performance and Reliability of Power Boiler by Monitoring Thermal and Strength Parameters
}

\author{
Tomasz Sobota ${ }^{1, *}$ \\ ${ }^{1}$ Cracow University of Technology, Institute of Thermal Power Engineering, Al. Jana Pawła II 37, 31-864 Cracow, Poland
}

\begin{abstract}
The paper presents a method for determination of thermo-flow parameters for steam boilers. This method allows to perform the calculations of the boiler furnace chamber and heat flow rates absorbed by superheater stages. These parameters are important for monitoring the performance of the power unit. Knowledge of these parameters allows determining the degree of the furnace chamber slagging. The calculation can be performed in online mode and use to monitoring of steam boiler. The presented method allows to the operation of steam boiler with high efficiency.
\end{abstract}

\section{Introduction}

The fouling processes caused by slagging and ash deposits are strongly affected by the kind of coal [1-6]. They become more intense if coal is co-fired with biomass. In the case of the furnace chamber, the fouling processes are different on its individual walls. Depending on the furnace chamber aerodynamics, local slag overhangs may be formed in the burner area or at other locations on the chamber walls. In places where temperature is high, such as the platen superheater area, the superheater surface slagging may also be caused by melted drops of ash forming deposits on the surface of tubes [7]. If biomass is co-fired, due to the low melting point of ash, intense processes of ash deposit formation and slagging may occur on the superheater stages located in zones with a lower flue gas temperature.

Ash fouling processes also affect the lifetime of the boiler superheaters [8-10]. It should be noted that about $40 \%$ of the boiler failures are caused by damage to boiler superheaters.

For this reason, there is a need to develop an effective and efficient method of determination of thermo-flow parameters for steam boilers. The presented in this paper method allows to the operation of steam boiler with high efficiency.

\section{Calculations of the boiler furnace chamber}

The degree of fouling of the boiler furnace chamber walls may be assessed by an online mode determination of the flue gas temperature at the furnace chamber outlet $T_{f e}$, the heat flux absorbed by the furnace chamber walls $\dot{Q}_{r}$ and the heat effectiveness $\psi$ of the furnace chamber walls. The outlet of the combustion chamber is located directly beneath of the platen superheater at a height of
$29 \mathrm{~m}$ (Fig. 1a). Adopted position of the outlet section of the furnace is consistent with the industrial definition, which says that the outlet from the furnace is where the spacing of the platens is less than $2.0 \mathrm{~m}$. The spacing of the platens is $0.7 \mathrm{~m}$ in the boiler analyzed in the paper. The heat effectiveness $\psi$ of the furnace chamber is defined as an average ratio of the heat flux absorbed by the water-wall to the heat flux falling on the water-wall of the combustion chamber.

Based on experimental data obtained from the testing of large power boilers, a formula containing parameter $M$, which characterizes the location where the maximum flame temperature occurs in the boiler was used [11]:

$$
\frac{T_{f e}}{T_{a d}}=\frac{B o^{0,6}}{M \varepsilon_{p a l}^{0,6}+B o^{0,6}}
$$

Parameter $M$ in Eq. (27) is a function of the kind of fuel (oil, gas or coal) and of the relative height at which burners are placed [11-13]. After temperature $T_{f e}$ is calculated from (1), the average heat flux $\dot{Q}_{r}$ absorbed by the furnace chamber walls may be determined.

The degree of slagging of the furnace chamber walls may be assessed determining the waterwall heat efficiency coefficient The $\psi$ coefficient gets smaller in proportion to slagging of the furnace chamber walls. If the furnace chamber walls are covered with a layer of slag, the temperature of the slag surface is high and the density of the heat flux $\dot{q}$ absorbed by the wall (i.e. the wall thermal load) is much smaller than in the case of a clean wall.

Slagging of the furnace chamber walls results in an increase in the flue gas outlet temperature $T_{f e}$ and a decrease in the heat flux absorbed by the furnace chamber walls $\dot{Q}_{r}$.

* Corresponding author: tsobota@mech.pk.edu.pl 


\section{Determination of the average degree of the furnace chamber fouling}

The waterwall heat efficiency coefficient $\psi$ will be determined in an online mode from the following nonlinear equation:

$$
\dot{m}_{p a r}^{z m}=\dot{m}_{p a r}^{o b l}(\psi),
$$

where: $\dot{m}_{p a r}^{z m}$ and $\dot{m}_{p a r}^{o b l}$ denote properly measured and calculated mass flows of steam. The steam mass flow $\dot{m}_{p a r}^{o b l}$ is a function of the waterwall heat efficiency $\psi$ and it is calculated from the boiler evaporator energy balance. The symbol $\dot{m}_{p a r}^{z m}$ denotes the steam mass flow at the boiler drum outlet determined using the steam mass flow $\dot{m}_{p}$ measured at the boiler outlet and the water mass flows $\dot{m}_{w 1}$ and $\dot{m}_{w 2}$ fed into steam attemperator No. 1 and No. 2, respectively.

$$
\dot{m}_{p a r}^{z m}=\dot{m}_{p}-\dot{m}_{w 1}-\dot{m}_{w 2},
$$

The condition of equality of the calculated and measured values of the steam mass flow allows an assessment of the degree of the furnace chamber fouling $\zeta$.

The waterwall heat efficiency coefficient $\psi$ is equal to the product of the waterwall shape factor $x$, which for tight walls in the OP-380 boiler is equal to unity, multiplied by the fouling coefficient $\zeta$ of the chamber furnace heating surfaces:

$$
\psi=x \zeta,
$$

where: $x=1$ for membrane water-walls used in the boiler studied.

Determining $\zeta$ so that the calculated and measured values of the boiler efficiency are the same, it is possible to assess the average degree of the fouling of the walls of the furnace chamber.

Owing to this way of determining the value of $\zeta$, the temperature of flue gases at the outlet from the furnace chamber $T_{f e}$ may be calculated much more accurately. If the fouling of the chamber walls is higher, the waterwall efficiency coefficient decreases: $\psi=\zeta$. The heat flux absorbed by the boiler evaporator $\dot{Q}_{p a r}$ gets smaller and the flue gas temperature at the furnace chamber outlet gets higher. As a result, there is a reduction in the steam mass flow generated in the evaporator and directed to the superheaters, which, at a higher flue gas temperature $T_{f e}$, causes an increment in the reheated steam temperature (at the same mass flow of fuel: $\dot{Q}_{p a l}$ ). In order to maintain the reheated steam temperature at the set level, bigger mass flows of water fed into the reheated steam attemperators are necessary.

Also the flue gas temperature after individual superheater stages rises due to the fouling of the furnace chamber walls.

The following quantities:

- the waterwall heat efficiency $\psi$,

- the mass flow rates of water $\dot{m}_{w 1}$ and $\dot{m}_{w 2}$ injected into attemperators,

- the flue gas temperature after individual superheater stages are strongly dependent on the degree of the fouling of the furnace chamber walls. If $\psi$ is reduced, and $\dot{m}_{w 1}$ and $\dot{m}_{w 2}$, as well as $T_{s p}$, after individual stages reach permissible set values, the steam slag and ash blowers in the furnace chamber should be activated.

Apart from the above-mentioned indices characterizing the fouling of the boiler heating surfaces in terms of heat exchange, the increase in the flue gas subatmospheric pressure after the superheater stages located further down the convective duct (at a higher distance from the furnace chamber) is another significant symptom of the fouling of the boiler - mainly of the surfaces of superheaters. Increased aerodynamic resistance caused by ash fouling of superheaters leads to a higher power consumption of the fans. The measurement of the flue gas pressure and of the engine power capacity may also be used to assess the degree of ash fouling of superheaters.

\section{Mathematical model of the boiler evaporator}

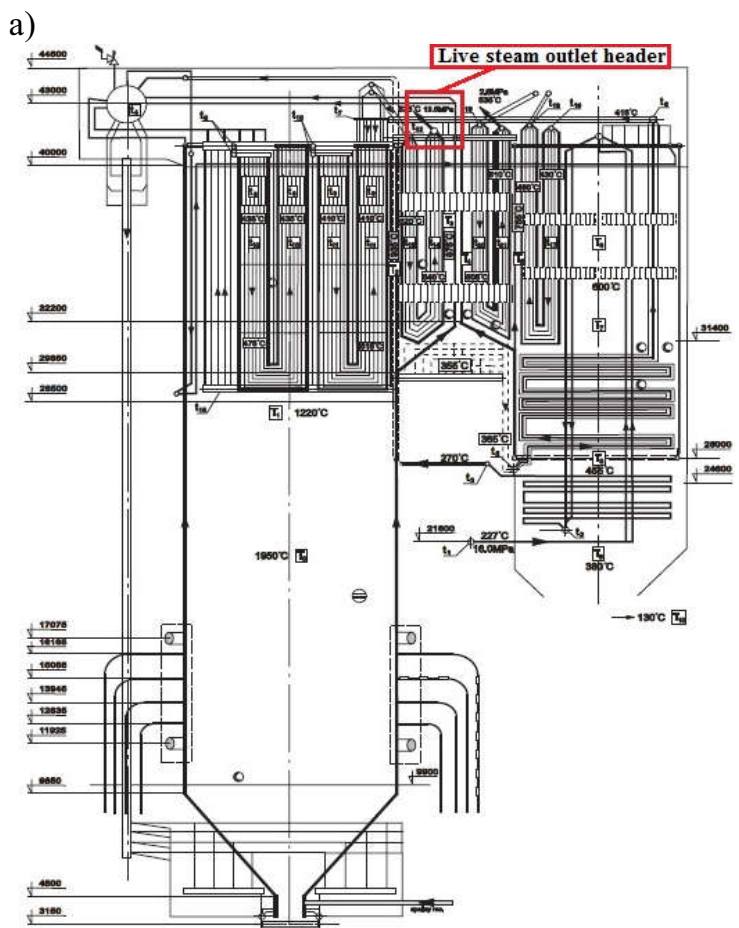

b)

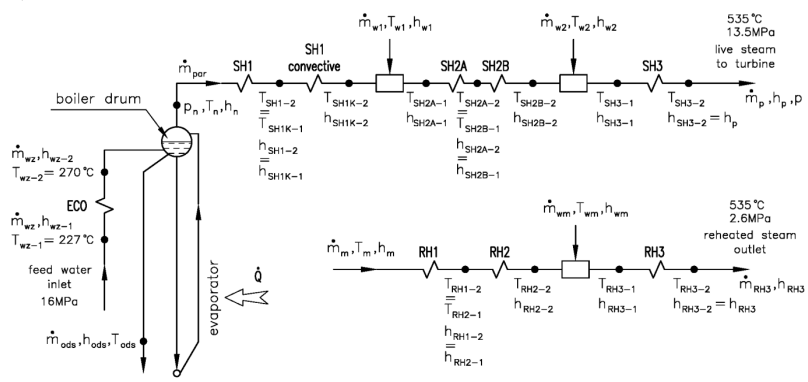

Fig. 1. Natural circulation steam boiler OP-380 with capacity of $380 \cdot 10^{3} \mathrm{~kg} / \mathrm{h}$ : a) longitudinal cross-section of the boiler, b) diagram of control volume for the boiler evaporator mass and energy balance 
The live steam mass flow is calculated from the boiler evaporator mass and energy balance (Fig. 1b):

$$
\begin{gathered}
\dot{m}_{w z}=\dot{m}_{p}-\dot{m}_{w 1}-\dot{m}_{w 2}+\dot{m}_{o d s}, \\
\dot{m}_{w z} h_{w z-2}+\dot{Q}_{p a r}= \\
=\dot{m}_{o d s} \cdot h^{\prime}\left(p_{n}\right)+\left(\dot{m}_{p}-\dot{m}_{w 1}-\dot{m}_{w 2}\right) \cdot h^{\prime \prime}\left(p_{n}\right)
\end{gathered}
$$

Substitution of (5) in (6) results in:

$$
\begin{aligned}
& \dot{m}_{p}=\frac{\dot{Q}_{p a r}}{h^{\prime \prime}\left(p_{n}\right)-h_{w z-2}}-\dot{m}_{o d s} \frac{h^{\prime}\left(p_{n}\right)-h_{w z-2}}{h^{\prime \prime}\left(p_{n}\right)-h_{w z-2}}+ \\
& +\dot{m}_{w 1}+\dot{m}_{w 2}
\end{aligned}
$$

where $\dot{Q}_{p a r}$ is the heat flux transferred from flue gases to the evaporator via radiation and convection.

The heat flux $\dot{Q}_{p a r}$ may be calculated from the following expression:

$$
\dot{Q}_{p a r}=\dot{Q}-\left.\dot{m}_{g} \cdot c_{p, g}\right|_{0} ^{T_{f e}-273.15}\left(T_{f e}-273.15\right),
$$

where $\dot{Q}$ is the heat flux brought to the furnace chamber with fuel and air, and which is defined as:

$$
\dot{Q}=\left.\dot{m}_{g} \cdot c_{p, g}\right|_{0} ^{T_{a d}-273.15} \cdot\left(T_{a d}-273.15\right),
$$

The symbol $T_{f e}$ denotes the flue gas temperature at the furnace chamber outlet.

It should be added that both efficiency and thermal calculations require the development of many functions and programs used for the calculation of thermal properties of water, saturated and superheated steam, and flue gases.

\section{Determination of fuel mass flow rate}

The calculation of the fuel mass flow rate is based on the fuel chemical composition or on the coal calorific value. The second approach is more appropriate for practical applications since the chemical composition of the coal is not determined continuously. Boiler efficiency is determined online by the indirect method [6, 14]. According to the ASME Performance Test Codes: PTC 4 - Fired Steam Generators [15] the stack gas temperature is corrected for air heater leakage based on $\mathrm{O}_{2}$ difference between flue gas into air heater and flue gas $\mathrm{O}_{2}$ leaving air heater. After correcting the temperature of the flue gas exiting the boiler the thermal efficiency of the boiler is calculated.

Based on the boiler efficiency $\eta$ determined in an online mode, the coal mass flow is calculated from the definition of the boiler heat efficiency

$$
\begin{aligned}
& \eta=\frac{\dot{Q}_{n}}{\dot{Q}_{h}}=\frac{\left(\dot{m}_{p}-\dot{m}_{w 1}-\dot{m}_{w 2}\right)\left(h_{p}-h_{w z-2}\right)}{\dot{m}_{p a l} W_{d}}+ \\
& +\frac{\left[\left(\dot{m}_{w 1}+\dot{m}_{w 2}\right) h_{p}-\dot{m}_{w 1} h_{w 1}-\dot{m}_{w 2} h_{w 2}\right]}{\dot{m}_{p a l} W_{d}}+ \\
& +\frac{\dot{m}_{o d s}\left(h_{n}-h_{w z-2}\right)}{\dot{m}_{p a l} W_{d}}+\frac{\dot{m}_{m}\left(h_{R H 1-2}-h_{R H 1-1}\right)}{\dot{m}_{p a l} W_{d}}-\frac{\dot{m}_{w m} h_{w m}}{\dot{m}_{p a l} W_{d}} \\
& +\frac{\dot{m}_{m}\left(h_{R H 2-2}-h_{R H 2-1}\right)}{\dot{m}_{p a l} W_{d}}+\frac{\left(\dot{m}_{m}+\dot{m}_{w m}\right)\left(h_{R H 3-2}-h_{R H 3-1}\right)}{\dot{m}_{p a l} W_{d}}
\end{aligned}
$$

Heat balance across the superheater attemporators is used to determine spray water mass flows. The fuel mass flow rate at various boiler loads is determined from Eq. (10) taking into account that the boiler efficiency $\eta$ is known,

$$
\begin{aligned}
& \dot{m}_{p a l}=\frac{\left(\dot{m}_{p}-\dot{m}_{w 1}-\dot{m}_{w 2}\right)\left(h_{p}-h_{w z-2}\right)}{\eta W_{d}}+ \\
& +\frac{\left[\left(\dot{m}_{w 1}+\dot{m}_{w 2}\right) h_{p}-\dot{m}_{w 1} h_{w 1}-\dot{m}_{w 2} h_{w 2}\right]}{\eta W_{d}}+ \\
& +\frac{\dot{m}_{o d s}\left(h_{n}-h_{w z-2}\right)}{\eta W_{d}}+\frac{\dot{m}_{m}\left(h_{R H 1-2}-h_{R H 1-1}\right)}{\eta W_{d}}+ \\
& +\frac{\dot{m}_{m}\left(h_{R H 2-2}-h_{R H 2-1}\right)-\dot{m}_{w m} h_{w m}}{\eta W_{d}}+ \\
& +\frac{\left(\dot{m}_{m}+\dot{m}_{w m}\right)\left(h_{R H 3-2}-h_{R H 3-1}\right)}{\eta W_{d}} .
\end{aligned}
$$

Equations (10) and (11) are valid only for steady state conditions. The symbols: $h_{w z-2}, h_{n}, h_{w 1}, h_{w 2}, h_{o d s}, h_{p}, h_{R H 3}$ in equations (10) and (11) denote, respectively, the enthalpy of: feed water after the economizer, steam saturated at the boiler drum pressure, injection water in superheated steam attemperators, brine, live steam at the boiler outlet, and reheated steam at the boiler outlet (Fig. 2).

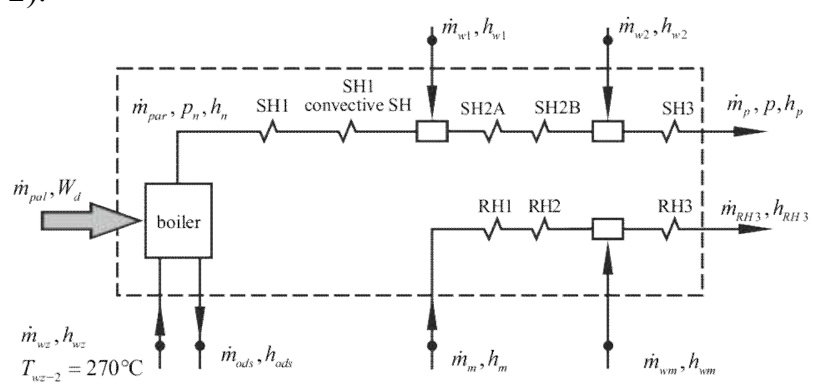

Fig. 2. Diagram of control volume for the boiler mass and energy balance

The calculations of the volume and mass flow rates of the flue gases are based on the determined fuel mass flow rate. Based on the determined excess air number $\lambda$ using the expression: $\lambda=21 /\left(21-\mathrm{O}_{2}\right)$, defined as the ratio of the air to the air flow rate required theoretically, the volume and mass flows of moist flue gases are found. The symbol $\mathrm{O}_{2}$ denotes the volume fraction of oxygen in the flue gas.

\section{Calculation of heat flow rates absorbed by superheater stages and monitoring the degree of fouling of superheaters and reheaters}

The degree of fouling of the $i$-th superheater stage with ash $\xi_{i}$ is calculated continuously from the following expression:

$$
\xi_{i}=\frac{\dot{Q}_{i, z}}{\dot{Q}_{i, c}}
$$


where: $\dot{Q}_{i, z}$, in $\mathrm{W}$, denotes the heat flow rate absorbed by the superheater stage affected by fouling, and $\dot{Q}_{i, c}$, in $\mathrm{W}$, is the heat flow rate absorbed by a clean superheater stage. The heat flow rate $\dot{Q}_{i, c}$ at a given value of the excess air number $\lambda$ is a function of the boiler load. After the boiler is thoroughly cleaned, the measurements of $\dot{Q}_{i, c}$ are made depending on the steam mass flow rate $\dot{m}_{i}$ flowing through a given superheater stage. The advantage of formula (12) is no need for measuring the temperature of the flue gas after the each superheater stage, which is especially difficult in the regions of high flue gas temperatures.

If the excess air ratio in the boiler or the slagging of the waterwalls of the combustion chamber vary greatly over time, the fouling factor calculated from the formula (12) can lead to less accurate results. An alternative way to assess the degree of ash fouling of a superheater stage is the ratio of the current overall heat transfer coefficient $U_{i, z}$ versus overall heat transfer coefficient for the clean surface $U_{i, c}$.

$$
\xi_{U, i}=\frac{U_{i, z}}{U_{i, c}}
$$

The overall heat transfer coefficient $U_{i}$ related to the surface area $A_{i}$ is calculated in the on-line mode using the following relationship:

$$
U_{i}=\frac{\dot{Q}_{i}}{A_{i} \cdot \Delta T_{m, i}}
$$

where the symbol $\Delta T_{m, i}$ denotes the mean logarithmic temperature difference (LMTD) between the flue gas and steam. The flue gas temperature at the outlet of the combustion chamber and before each superheater stage was calculated based on the flue gas temperature measured after the last superheater stage in the flue gas duct. The flue gas temperature is then low and easier to measure.

Assuming that the measured value of the flue gas temperature after the entire superheater in known, the flue gas temperature before each stage of the superheater including flue gas temperature at the outlet of the combustion chamber can be determined sequentially.

Knowing the heat flow rate $\dot{Q}_{i, c}$ absorbed by the clean $i$ th stage of the superheat at a given boiler load and heat flow rate $\dot{Q}_{i, \mathrm{z}}$ absorbed by the fouled $i$-th stage at the same load of the boiler the fouling degree of the $i$-th superheater stage can be evaluated in the on-line mode. Pre-setting the limiting value of the fouling degree $\xi_{i}$ for $i$-th superheater stage, the frequency of sootblowers activating can be controlled. If the fouling degree $\xi_{i s}$ lowers below the prescribed limit then the sootblower is activated. Steam and water enthalpies were determined using International Steam Tables [16]. The heat flux measurements using different methods are presented in [17-20].

\section{On-line monitoring of the steam boiler thermo-flow parameters}

The ability to monitor the thermo-hydraulic parameters of steam power boiler is shown on the example of OP380 unit used in CHP Krakow S.A. RAFAKO design OP-380 steam boiler is drum type, radiant, pulverized coal fired boiler, with natural circulation. Its characteristic is shown in Table 1.

Table 1. Characteristic of the OP-380 power boiler

\begin{tabular}{|l|c|}
\hline \multicolumn{1}{|c|}{ Boiler type } & With natural circulation \\
\hline Firing system & Tangential \\
\hline Output capacity & $105,6 \mathrm{~kg} / \mathrm{s}$ \\
\hline Live steam temperature & $540^{\circ} \mathrm{C}$ \\
\hline Live steam pressure & $13,9 \mathrm{MPa}$ \\
\hline Reheated steam temperature & $540^{\circ} \mathrm{C}$ \\
\hline Reheated steam pressure & $2,65 \mathrm{MPa}$ \\
\hline Feed water temperature & $227^{\circ} \mathrm{C}$ \\
\hline Boiler efficiency & $91 \%$ \\
\hline Fuel type & $\mathrm{Hard}$ coal \\
\hline Fuel low heating value & $21,0 \mathrm{MJ} / \mathrm{kg}$ \\
\hline
\end{tabular}

The Figs. $3 a$ and $3 b$ shows the time changes of the fuel and live steam mass flow rates and also changes in the excess air ratio and the boiler efficiency. Fig. 3a shows the stable operation of the boiler close to nominal capacity. Throughout the time period the value of the excess air ratio does not change, and the boiler efficiency is high - in the range of $91.6 \%-92.0 \%$.
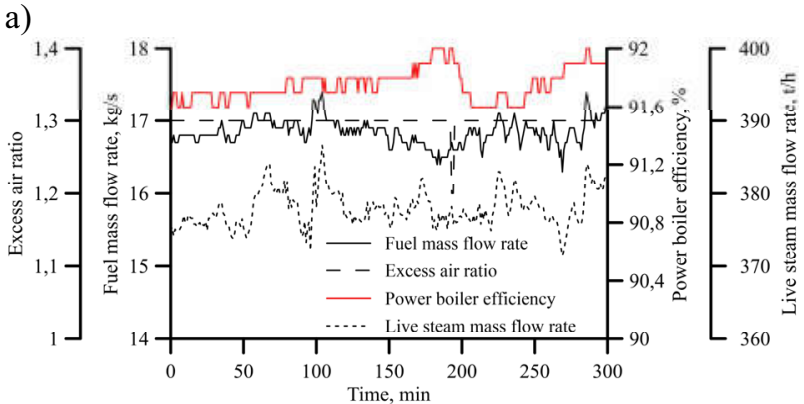

b)

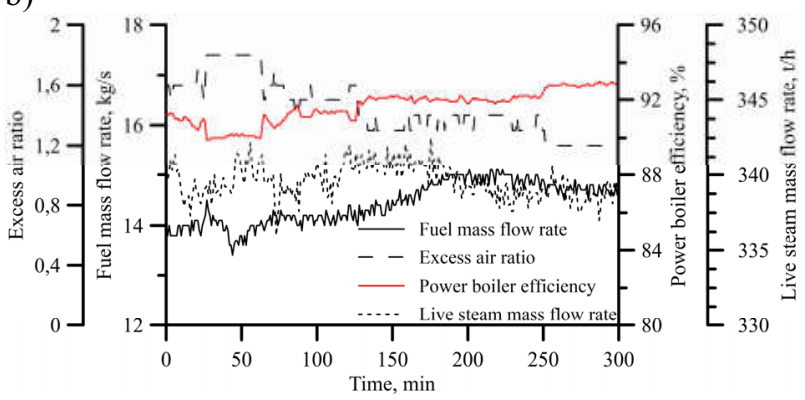

Fig.3. Live steam and fuel mass flow rates, excess air ratio and efficiency of the power boiler time distributions

A different situation is presented in Fig. 3b. This figure shows large time variation of the excess air ratio. In the first part of the analyzed interval excess air ratio reaches a value of approx. 1.6 which is accompanied by a decrease of the boiler efficiency up to $90 \%$. It is 
associated with high temperature in the combustion chamber and hence a large heat losses in the flue gases. In the second part of the diagram $3 b$ excess air ratio decreases to 1.2 , which is a typical value for this type of boiler. This situation is reflected into an increase in boiler efficiency above $92 \%$.

Heat flow rates received by the power boiler evaporator (Fig. 4), live steam superheater (Fig. 5) and steam reheater are also monitored.

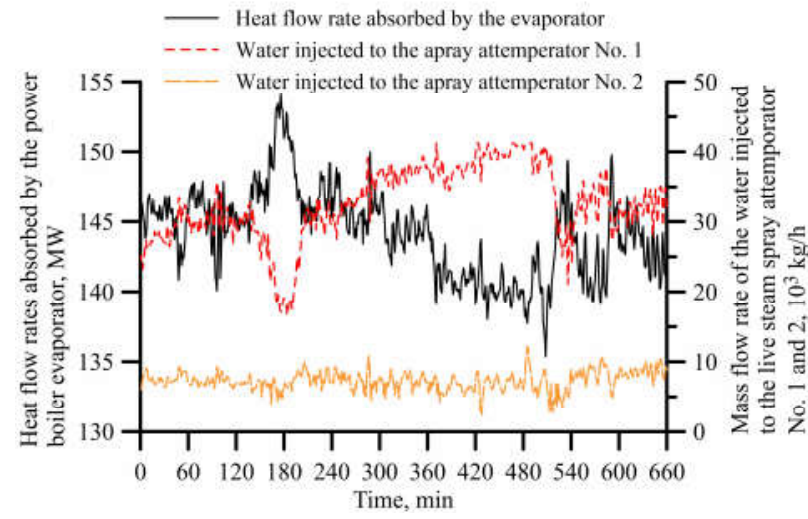

Fig. 4. Time distribution of the heat flow rate absorbed by the boilers evaporator

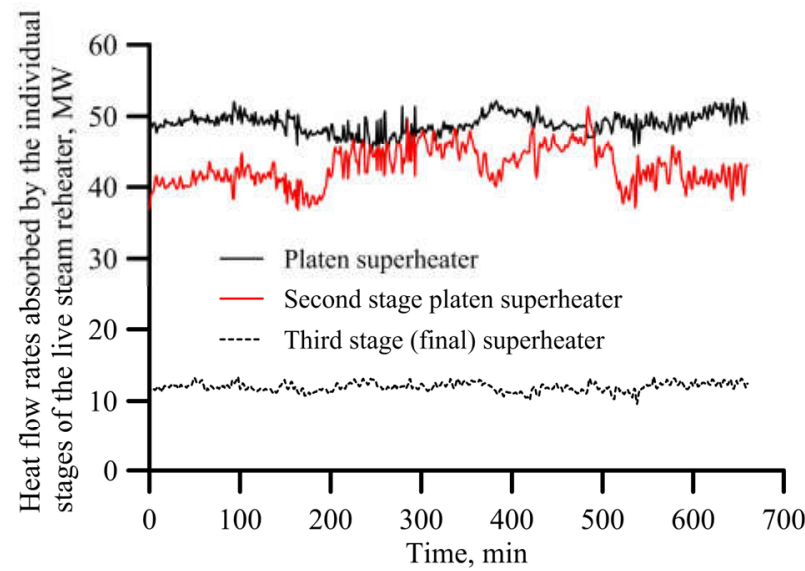

Fig. 5. Time distribution of the heat flow rates absorbed by the live steam superheater stages

On-line monitoring of the heat flux received by the steam boiler heating surfaces can be used to assess the fouling and slagging degree of the combustion chamber and live steam superheater. The increase in fouling of the combustion chamber is reflected by a decrease in live steam flow. This information can be a signal for the operator to start the boiler water or steam soot blowers.

\section{Stress monitoring}

High thermal stresses can occur in partially filled horizontal vessels. Thermal stresses in the cylindrical elements are caused by the occurrence of temperature differences both in the radial and circumferential direction. In practice, the thermal stresses due to temperature drop over the tube wall are monitored. The stresses caused by the occurrence of a temperature difference on the thick-walled component circumference are rarely monitored.

The calculations performed using the finite element method (FEM) show, however, that the temperature difference occurring at the periphery of the horizontal cylindrical element (header) can lead to much higher stresses than the stresses caused by the radial temperature difference.

During operation under transient conditions, for example, during power plant start-up and shut-down, there are significant temperature differences over the circumference of the horizontal pressure vessels [21-22]. This phenomenon is caused by the different heat transfer coefficients in the water and steam spaces. This takes place in large steam generator drums, superheater headers and steam pipelines. Water steam condensate collects at the bottom of the horizontal pressure elements, such as superheater headers and pipelines in case of malfunctioning drainage.

High thermal stresses caused by nonuniform temperature distribution on vessel circumference also occur in emergency situations such as fire of partially filled fuel tanks. Thermal stresses can limit the heating and cooling rates of temperature changes in power boiler thickwalled pressure components. The largest absolute value of thermal stresses appears at the inner surface. Direct measurements of these stresses are very difficult to take, since the inner surface is in contact with water or steam under high pressure. For that reason, thermal stresses are calculated in an indirect way based on measured temperatures at selected points, located on an outer thermally insulated surface of a pressure element.

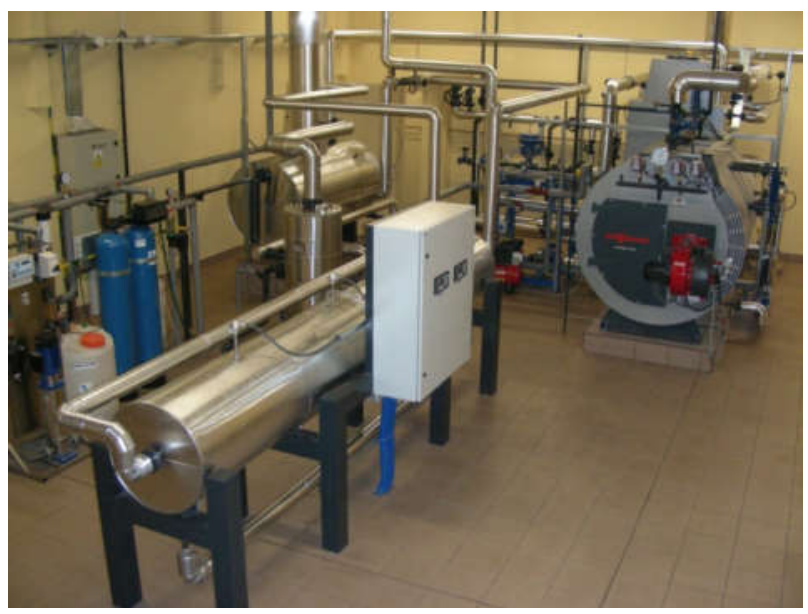

Fig. 6. View of the experimental installation for testing the computer system for on-line monitoring thick-wall pressure components

In order to validate the developed method for stress monitoring, modern experimental installation was built (Fig. 6). In the design, particular emphasis was placed on ensuring that the conditions are similar to those that may occur in pressure components installed in power plants. In addition to measuring of the metal temperature, mass flow rate, and pressure of the steam were measured as a function of time. To measure temperature distribution on 
the outer surface of the steam header pre-calibrated thermocouples were used.

The experimental installation consists of the following elements: steam generation unit with steam output capacity $700 \mathrm{~kg} / \mathrm{h}$, installation for boiler feed water treatment, cascade-type deaerator, steam pressure reduction station ( 10 bar $/ 4$ bar $/ 2$ bar), boiler control system, steam header made of martensitic high alloy P91 steel. a)

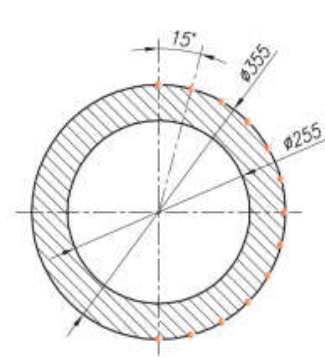

c)

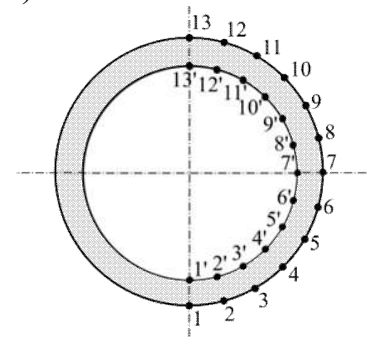

b)

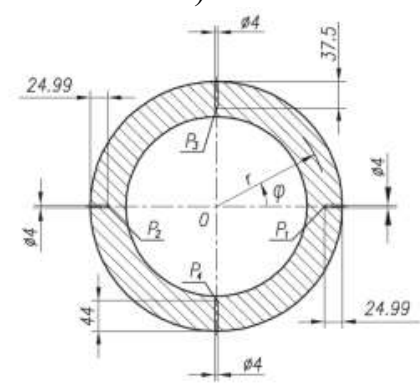

d)

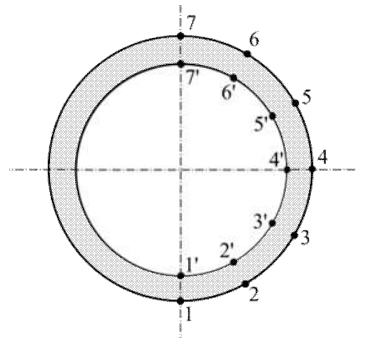

Fig. 7. Location of temperature sensors for measuring the header temperature: (a) thermocouples for temperature measuring at the outer surface of the steam header, (b) location of interior thermocouples used for experimental validation of the inverse procedure, (c) numbering of thirteen measuring points (1-13) and their counterparts at the inner surface, (d) numbering of seven measuring points (1-7) and their counterparts at the inner surface

The measurements of temperature carried out on the outer surface of the steam header will be used for the determination of the temperature and stress distributions at the wall cross-section including the inner and outer surfaces of the steam header using the inverse heat conduction methods. Points on the outer surface of a header, at which thermocouples are installed are shown in Figs. 7c and 7d. Thirteen temperature sensors are uniformly spaced every 15 degrees at half the circumference (Fig. 7c). If the temperature of the tube outer surface is measured at seven points a spacing of temperature sensors is 30 degrees.

The steam header was made out of the ferriticmartensitic high alloy P91 steel $(0.08 \% \mathrm{C}, 0.2 \% \mathrm{Si}, 0.3$ $\mathrm{Mn}, \leq 0.02 \% \mathrm{P}, \leq 0.015 \% \mathrm{~S}, \leq 0.04 \% \mathrm{Al}, \quad 8 \% \mathrm{Cr}$, $0.85 \div 1.05 \%$ Mo, $0.06 \div 0.1 \%$ Mo, $\leq 0.4 \%$ Ni). The following physical properties of the P91 steel have been adopted for calculations: specific heat, $c=486 \mathrm{~J} /(\mathrm{kg} \cdot \mathrm{K})$, thermal conductivity, $k=29 \mathrm{~W} /(\mathrm{m} \cdot \mathrm{K})$, density, $\rho=7750$ $\mathrm{kg} / \mathrm{m}^{3}$, modulus of elasticity, $E=2.28 \cdot 10^{11} \mathrm{~Pa}$, Poisson's ratio, $v=0.29$, coefficient of linear thermal expansion $\beta$ $=0.098 \cdot 10^{-4} 1 / \mathrm{K}$. The outer diameter $d_{\text {out }}$, wall thickness $\delta$ and the length $L$ are: $355 \mathrm{~mm}, 50 \mathrm{~mm}$ and $3765 \mathrm{~mm}$, respectively. Thirteen thermocouples $\mathrm{NiCr}-\mathrm{NiAl}$ (Ktype) were mounted every $15^{\circ}$ on the half of the outer circumference at the distance of $2150 \mathrm{~mm}$ from the inlet of steam (Fig. 7a).

The actual temperatures measured at the outer surface of the steam header were used in the analysis.

To validate the inverse technique developed in the paper, four thermocouples were installed at the interior locations: $\delta_{1}=\delta_{2}=d_{\text {out }}-0.50 \delta, \delta_{3}=d_{\text {out }}-0.75 \delta$ and $\delta_{4}$ $=d_{\text {in }}+6 \mathrm{~mm}$ (Fig. 7b), where the symbol $\delta$ denotes the tube thickness. These measurements were carried out with sheathed thermocouples $\mathrm{NiCr}-\mathrm{NiAl}$ (K-type) with outer diameter of $3 \mathrm{~mm}$. The temperature and thermal stress on the internal surface of the header are based on the metal temperature measured at the 13 or 7 points on the outer surface to evaluate the effect of the number of temperature measuring points on the accuracy of the solution of the inverse problem.

a)

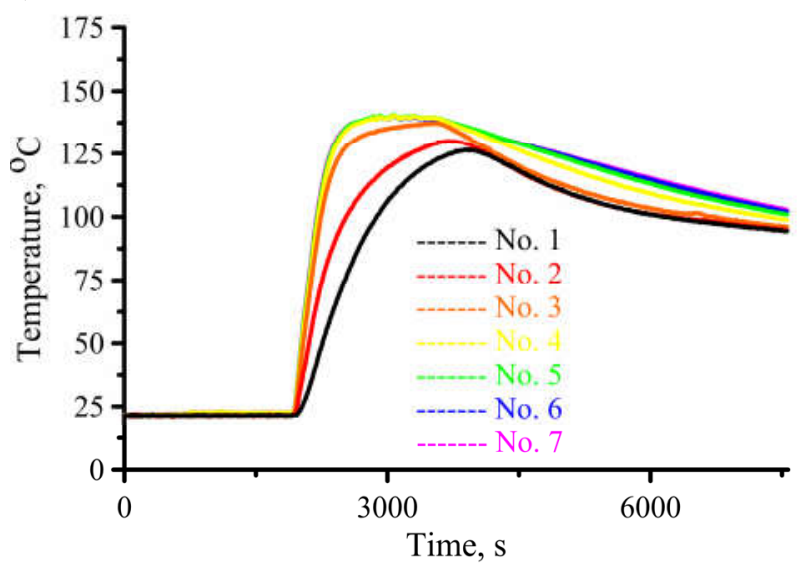

b)

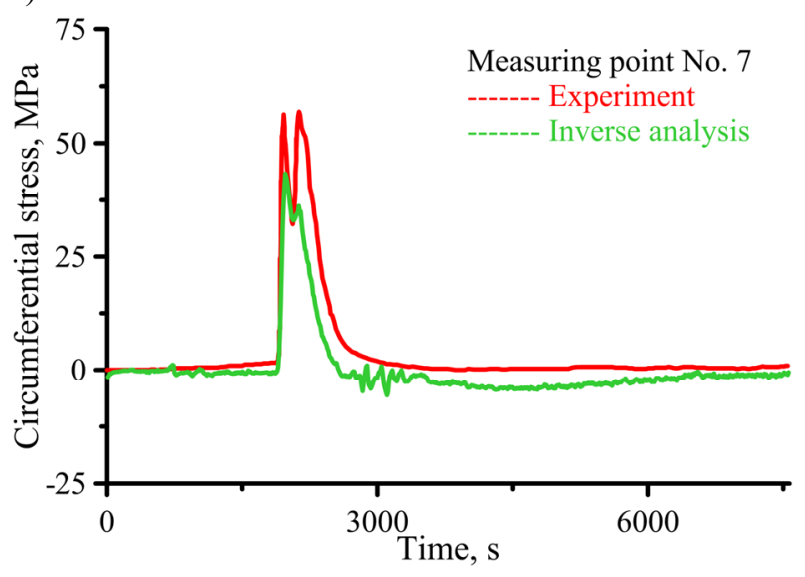

Fig. 8. Measured temperature at 7 points situated on the outer surface of the header (a) and comparison of the circumferential thermal stress obtained using inverse analysis with the experimentally determined stress using strain gauges (b)

Figure 8 illustrates a satisfactory agreement between measured and calculated stresses at the measuring point No. 7 (Fig. 7d).

Extensive comparisons of temperature and thermal stress distributions, obtained by measuring the temperature at 7 and 13 points showed that satisfactory accuracy is also 
achieved for seven measuring points. Therefore, the critical elements of the boiler pressure metal temperature is measured on the outer surface at seven points. This is also advantageous because of the lower cost of installing temperature sensors.

The temperatures measured at seven points (22-28) on the outer surface of the monitored cylindrical component (Fig. 9) were used for the determination of the temperature and stress distributions at the wall crosssection including the inner surface. Fig. 9 shows the finite volume mesh used to solve the inverse heat conduction problem in on-line mode. Based on the estimated temperature distribution at the cross-section, thermal stresses were computed using the FEM (Finite Element Method).

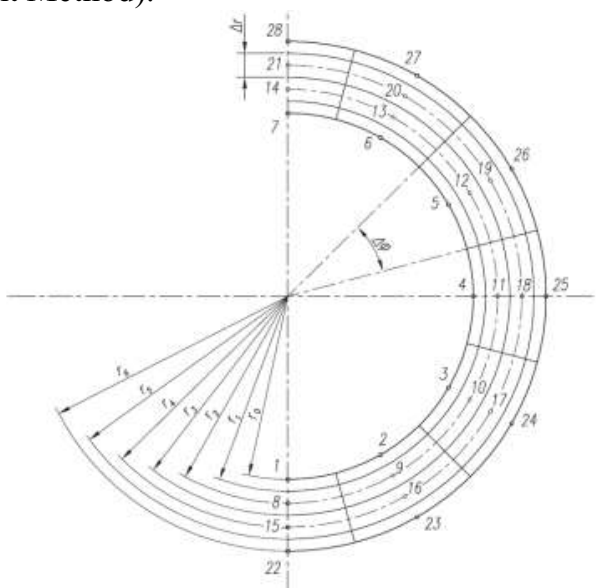

Fig. 9. Division of the steam header cross-section into finite volumes

a)

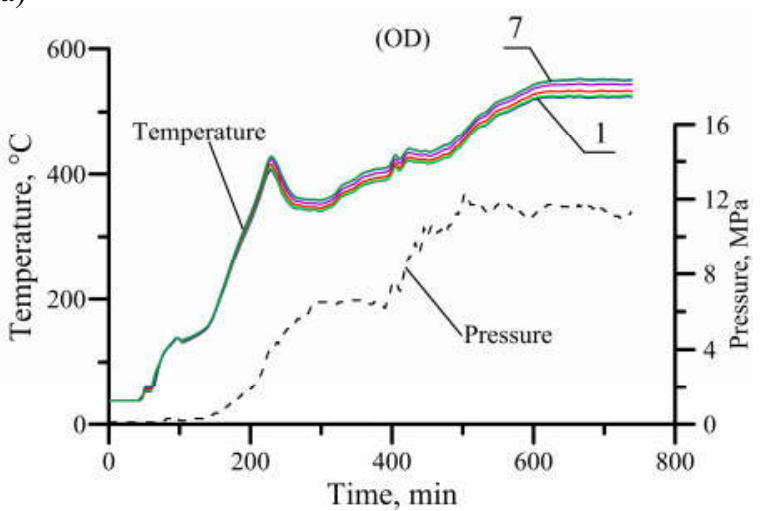

b)

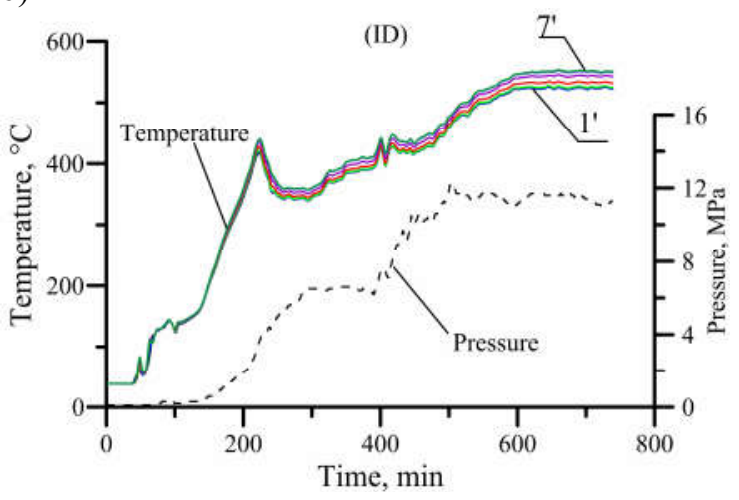

Fig. 10. Time distribution of the temperature measured on the outer surface OD (a) and calculated on the inner surface ID (b)
Selected results for a boiler start-up from a cold state are depicted in Figs. 10-13. Thermal and pressure caused stresses at monitored outlet header of the final superheater stage are shown in Figs. 12-13. The steam header has outer diameter of $324 \mathrm{~mm}$ and wall thickness of $70 \mathrm{~mm}$, and is manufactured of 10 CrMo 9-10 steel. The chemical composition of 10 CrMo 9-10 steel shows Table 2 .

Table 2. The chemical composition of 10 CrMo 9-10 steel

\begin{tabular}{|c|c|c|c|c|c|c|c|}
\hline & $\mathrm{Si}$ & $\mathrm{Mn}$ & $\mathrm{P}$ & $\mathrm{S}$ & $\mathrm{Cr}$ & Mo & $\mathrm{Cu}$ \\
\hline $\begin{array}{l}08- \\
14\end{array}$ & .50 & $\begin{array}{l}0.40- \\
0.80\end{array}$ & .02 & 0.01 & $\begin{array}{l}2.00- \\
2.50\end{array}$ & $\begin{array}{l}0.90- \\
1.10\end{array}$ & \\
\hline
\end{tabular}

The measured temperature histories are shown in Fig. 10a. The temperatures obtained from the solution of the inverse heat conduction problem are depicted in Fig. $10 \mathrm{~b}$.

Temperature variations on the header circumference for selected time points illustrates Fig. 11.

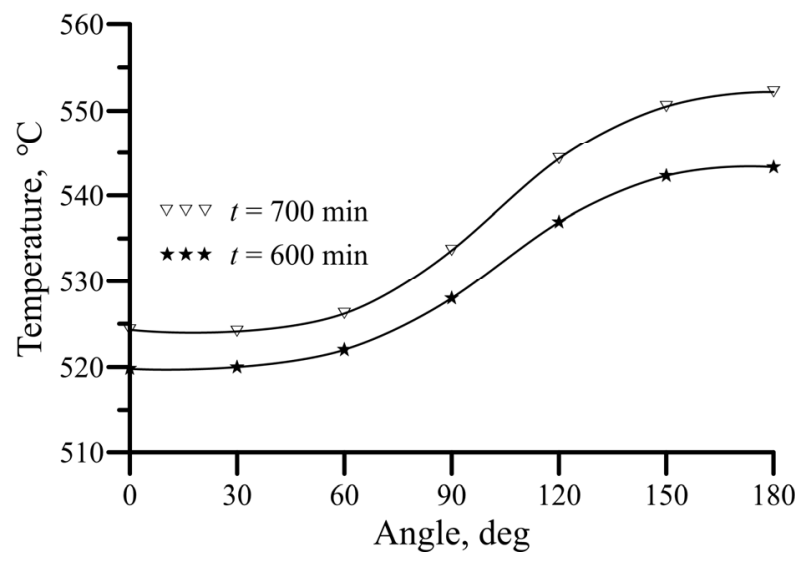

Fig. 11. Wall temperature on the outer surface of steam header as a function of an angle at different times

The temperature difference between the top and bottom of the header is within $25 \mathrm{~K}$ (Fig. 11).

After determining the temperature distribution the stresses due to temperature and inner pressure were calculated using the finite element method (FEM) of an unpierced cylinder with $S C C=1.0$. Circumferential and longitudinal stresses at the inner header surfaces as functions of time are shown in Fig. 12a and 12b, respectively.

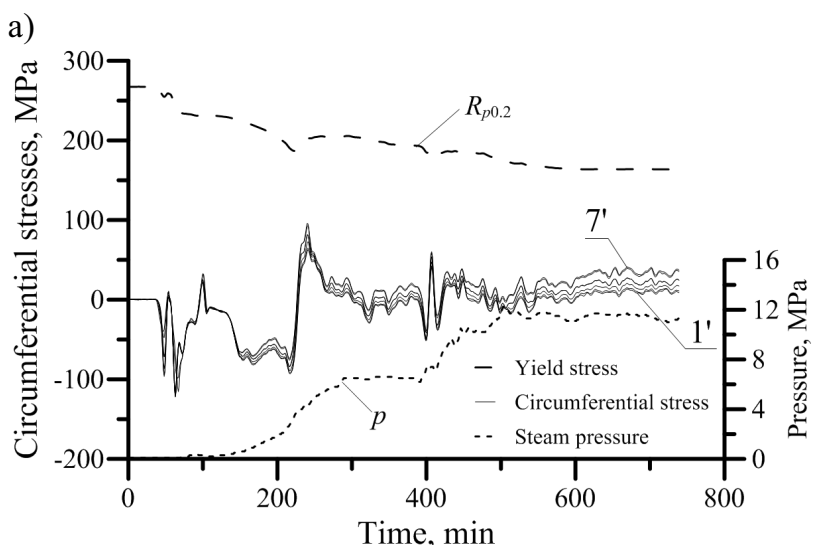


b)

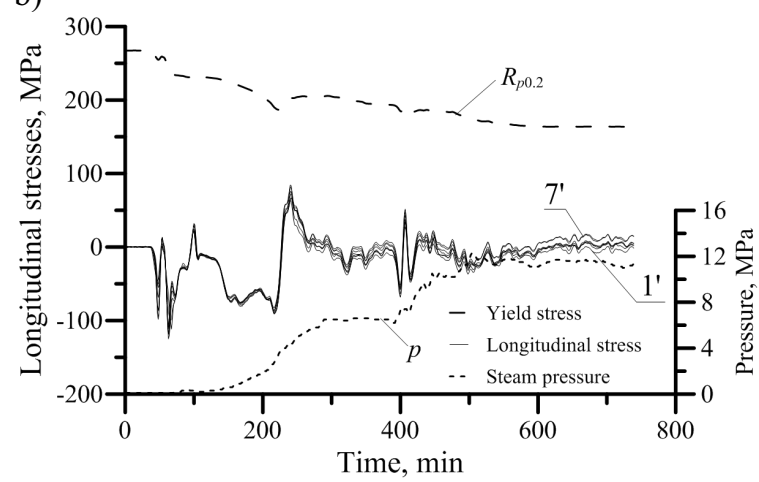

Fig. 12. Calculated circumferential (a) and longitudinal (b) stresses due to pressure and thermal loads at the inner surface of the outlet header of the final superheater; location of the points 1' -7 ' is shown in Fig. $7 \mathrm{~d}$ with $S C C$ $=1.0$.

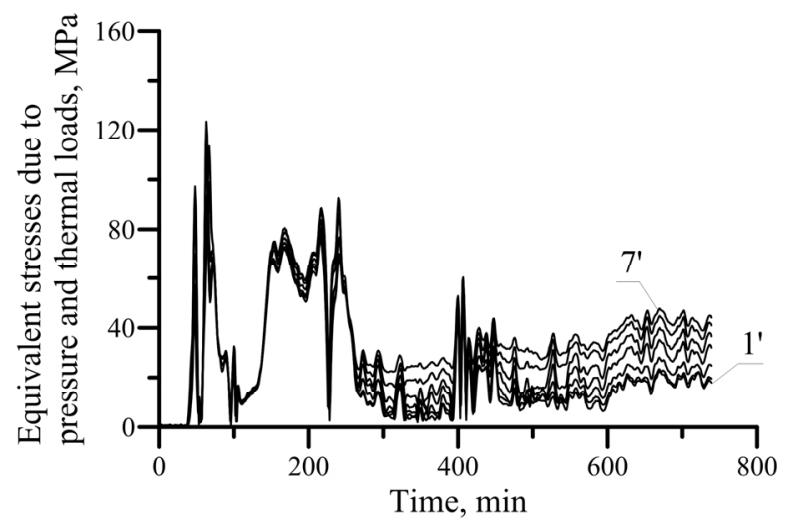

Fig. 13. Calculated equivalent stresses due to pressure and thermal loads at the inner surface of the outlet header of the final superheater; location of the points $1{ }^{\prime}-7$ ' is shown in Fig. 7d.

Time changes of equivalent stresses at seven locations on the inner header surface are presented in Fig. 13. The analysis of the results shown in Fig. 12-13 can see that the value of the stresses affect not only the pressure but also heat loads.

The analysis of the results depicted in Figs 12-13 shows that the circumferential and longitudinal stresses are less than the yield strength. It should be noted, however, that the stresses on the edges of the holes are high $(S C C=2.5$ or as in [17]) and may lead to plastic deformations, which in turn cause the thermal fatigue. The permissible tensile and compressive at the edge of the hole, calculated in accordance with EN 12952-3 [23] are respectively $323.97 \mathrm{MPa}$ and $241.83 \mathrm{MPa}$. Also the maximum stress on the edge of the opening is smaller than the specified allowable stresses. There are two operating procedures to reduce effectively the longitudinal and circumferential temperature differences after the boiler has been built: properly draining the horizontal header and slowing down the start-up rate. Also, at the design stage the flexibility of the boiler can be improved by providing spring supports for the headers to allow their significant deflection. To avoid large temperature differences on the circumference of headers multiple $35 \mathrm{~mm}$ drain connections at the header invert should be provided to ensure good drainage.

\section{Conclusion}

A computer system for thermo-hydraulic monitoring of the steam boilers delivers in on-line mode the following operation parameters: heat losses and boiler efficiency, coal mass flow rates, fouling and slagging degrees of the combustion chamber and all superheater stages. The local and average slagging degrees of combustion chamber walls are determined experimentally. The monitoring systems performs the on-line heat transfer calculations of the boiler combustion chamber and heat flow rates absorbed by superheater stages.

An important task of the computer system developed is also determining thermal stresses in critical pressure parts of the boiler and to estimate their remnant life. The proposed computer system ensures economical and safe operation of the boiler in steady states and during load changes. Due to the development of wind farms blocks in thermal power plants should be capable to rapid starts. By installing developed system start-up time of the boiler can be greatly reduced without the risk of overheating superheater tubes and shortening service life of the boiler structural elements.

Since the degree of slagging of the combustion chamber and degree of ash fouling of superheater stages are calculated in on-line mode, the computer system can be used to control the activating frequency of slag and ash blowers.

The ability of the developed system to monitor thermal and flow parameters, thermal stresses and lifetime of critical pressure components has been shown on example of a steam boiler with natural circulation.

\section{References}

1. H. Bilirgen, Slagging in PC boilers and developing mitigation strategies. Fuel, 115, pp. 618-624 (2014)

2. N.S. Harding, D.C. O'Connor, Ash deposition impact in the power industry, Fuel Processing Techn. 88, pp. 1082-1093 (2007)

3. L.M. Romeo, R. Gareta, Hybrid System for Fouling Control in Biomass Boiler, Eng. Apps. of Artificial Intelligence, 19, pp. 915-925 (2006)

4. L. M. Romeo, R. Gareta, Fouling Control in Biomass Boiler. Biomass and Bioenergy 33, pp. 854-861 (2009)

5. A.U. Syed, N.J. Simms, J.E. Oakey, Fireside corrosion of superheaters: Effect of air and oxy-firing of coal and biomass. Fuel, 101, pp. 62-73 (2012)

6. J. Taler, M. Trojan, D. Taler, Monitoring of Ash Fouling and Internal Scale Deposits in Pulverized Coal Fired Boilers, Nova Science Publishers, New York (2011)

7. M. Poniewski, A. Salij, J. Stępień, Impact of biomass co-firing on selected parameters of a $225 \mathrm{MW}$ power unit, J. of Power Techn., 95, pp. 84-90 (2015) 
8. H. Othman, J. Purbolaksono, B. Ahmad, Failure investigation on deformed superheater tubes. Eng. Failure Analysis, 16, pp. 329-339 (2009)

9. A.K. Ray, Y.N. Tiwari, R.K. Sinha, P.K. Roy, S.K. Sinha, R. Singh, S. Chaudhuri, Remnant life assessment of service-exposed pendent superheater tubes. Eng. Failure Analysis, 9, pp. 83-92 (2002)

10. P. Madejski, D. Taler,. Analysis of temperature and stress distribution of superheater tubes after attemperation or sootblower activation. Energy Conversion and Management, 97, pp. 131-137 (2013)

11. N.V. Kuznetsov, V.V. Mitor, I.E. Dubovskij, and E.S. Karasina, Thermal Calculations of Steam Boilers. Standard Method (Energy, Moscow, 1973)

12. A.G. Blokh, Heat Transfer in Steam Boiler Furnaces (Hemisphere, Washington, 1988)

13. S. Kakaç, Boilers, Evaporators, and Condensers (Wiley, New York, 1991).

14. J. Taler (Ed.), Thermal and Flow Processes in Large Steam Boilers. Modeling and Monitoring (WNT, Warsaw, 2011)

15. ASME PTC 4. Fired Steam Generators. Performance Test Codes (The ASME, New York, 2013)

16. W. Wagner, H. J. Kretzschmar, International Steam Tables Properties of Water and Steam Based on the Industrial Formulation IAPWS-IF97 (SpringerVerlag, Berlin, 2008)

17. J. Taler, D. Taler, P. Ludowski, Measurements of local heat flux to membrane water walls of combustion chambers, Fuel, 115, pp. 70-83 (2014)

18. J. Taler, D. Taler,. Measurement of Heat Flux and Heat Transfer Coefficient. Chapter 1, in: Heat Flux: Processes, Measurement Techniques and Applications, G. Cirimele and M. D'Elia (Eds.) (Nova Science Publishers New York, pp. 1-104, 2012)

19. P. Duda, J. Taler, A new method for identification of thermal boundary conditions in water wall tubes. Int. J. Of Heat an Mass Transfer, Vol. 52, Issues 5-6, pp. 1517-1524, (2009)

20. J. Taler, D. Taler, Measurements of Local Heat Flux and Water-Side Heat Transfer Coefficient in Water Wall Tubes, Chapter 1, in Heat Transfer, Editor : D. M. Salim Newaz Kazi (InTech, Rijeka - Shanghai, pp. 3-34, 2012)

21. J.M. Fetköter, D.J. Lauer, M. Wedemeyer, G. Engelhard, Replacement of Shutdown Cooling System and Repair of Nozzle Welds of Reactor Pressure Vessel in the Forsmark $1+2$ Nuclear Power Plant, VGB PowerTech, Vol. 81, No. 6, pp. 62-64 (2001)

22. P. Rop, Drum Plus: a drum type HRSG with Benson benefits. Modern Power Systems, Vol. 30, No. 10, pp. 35-40 (2010)

23. EN 12952-3 Water-tube boilers and auxiliary installations - Part 3: design and calculation for pressure parts. European Committee for Standardization, Brussels 